LAW, ETHICS AND MEDICINE

\title{
Ethical issues in psychopharmacology
}

\section{McHenry}

J Med Ethics 2006;32:405-410. doi: 10.1136/jme.2005.013185

The marketing of selective serotonin reuptake inhibitors in the psychopharmacological industry presents a serious moral problem for the corporate model of medicine. In this paper I examine ethical issues relating to the efficacy and safety of these drugs. Pharmaceutical companies have a moral obligation to disclose all information in their possession bearing on the true risks and benefits of their drugs. Only then can patients make fully informed decisions about their treatment.

$\mathrm{N}$ ow more than ever the moral and scientific integrity of psychopharmacology deserves close scrutiny. A behemoth pharmaceutical industry has created corporate psychiatry along with industry sponsored clinical research, direct to consumer marketing of antidepressants, ghost writing for medical journals and a major war for the market share. All the trappings are in place for marketing the disease rather than the cure. An illness intervention industry with no serious ethical commitment to health care threatens the most basic imperative of the medical art- "first, do no harm" —and demonstrates the weakness in the corporate model of medicine.

\section{THE SEROTONIN HYPOTHESIS}

The controversy over the serotonin hypothesis of depression lies at the very heart of the matter. Since, however, the pharmaceutical industry has an enormous financial interest in protecting the hypothesis, the problems with the theory are seldom discussed and less likely to reach publication. The epistemological virtue of science as the rigorous pursuit of truth has been corrupted by an industry that manipulates the process to its own advantage. Corporate psychiatrists become coconspirators by accepting a paradigm uncritically and by adopting the language game of chemical imbalance that entirely satisfies this purpose.

The serotonin hypothesis is a monoamine theory that advances the view that depression is caused by neurotransmitter system deficits. It was originally proposed in the late 1950s by George Ashcroft and Donald Eccleston at Edinburgh and gained further support from Alex Coppen at Surrey and Herman van Praag at Utrecht in the groundswell of early developments in biological psychiatry. ${ }^{2}$ Low concentrations of serotonin, 5HT (5-hydroxytryptamine) or its main metabolite, 5-HIAA (5-hydroxyindole acetic acid), were found in autopsy studies of brains from suicide victims and in studies of cerebrospinal fluid from depressed patients. ${ }^{3-6}$
Although it might appear that the development of the new psychotropic drugs, the selective serotonin reuptake inhibitors (SSRIs), was the next logical step from the idea of serotonin deficiency, the actual history shows otherwise. The norepinephrine hypothesis of depression (another monoamine theory), not the serotonin hypothesis, was the leading idea that guided research in psychopharmacology at the time, especially in the United States. The SSRIs were created when it became clear that drugs with an action on the serotonin system had a recognisably different effect from drugs active on the norepinephrine system. SSRIs function in the brain by blocking the breakdown or reuptake of serotonin from the synapse into the transmitting cell, thus leaving the serotonin active in the synapse for a longer period. " "Selective" in "SSRI" suggests that the drug's action is clean or precise, but this is misleading as the drug has effects on a range of other neurotransmitter systems.

Although the serotonin theory might offer a compelling view within our physiochemical model of the brain, its main problem is over simplicity in the overall neurochemical scenario. Even more to the point, however, it is probably false. The fact of the matter is that there never was a consistent body of evidence to support the theory. George Ashcroft, who was one of the pioneers in serotonin research, abandoned the idea of lowered serotonin levels by 1970 . Ashcroft makes the crucial point: "What we believed was that 5-HIAA levels were probably a measure of functional activity of the systems and not a cause. It could just as well have been that people with depression had low activity in their system and that 5-HIAA was mirroring that and then when they got better it didn't necessarily go up." ${ }^{\prime 9}$ With regard to Popperian and Kuhnian models of scientific advance, David Healy explains the survival of the monoamine theories despite a wealth of negative evidence. He describes them as erected on a quicksand of mistaken assumptions and apparently lacking in the mortar of supporting evidence. ${ }^{10}$ Although there seems to be no question about the fact that SSRIs act on the serotonin system, what has not been established is an abnormality of serotonin

Abbreviations: FDA, Food and Drug Administration; SSRI, selective serotonin reuptake inhibitors

' For a view wholly favourable to the development of SSRIs and their therapeutic benefits see P D Kramer's Listening to Prozac, especially chapter 3.7 David Healy offers an expanded history of this development and a counterargument to over inflated claims of the benefits of SSRIs in his Let Them Eat Prozac. ${ }^{8}$ 
metabolism in depression or that SSRIs correct a chemical imbalance. Instead of going back to the proverbial drawing board with Ashcroft, however, the pharmaceutical company marketing departments revived the serotonin theory in the late $1980 \mathrm{~s}$ and channelled all their financial might into promoting the SSRIs. It was a triumph of marketing over science. ${ }^{11}$

There are few neuroscientists today who would embrace the serotonin hypothesis. Whether this is true for prescribing physicians and psychiatrists is less clear. There are certainly those, perhaps the majority, who recognise that there are factors other than neurobiology involved in the aetiology, course and outcome of depressive disorders. My case against the serotonin hypothesis targets the manner in which this theory has been presented to the public by pharmaceutical industry marketing.

The success of the SSRIs no more demonstrates the causal relationship between serotonin deficiency and depression than the relief provided by aspirin for the cause of a fever. The aspirin might treat the symptoms, but this does not provide any important information about the cause of the fever. Similarly, the fact that a patient's depression might be treated by an SSRI tells us nothing about the cause of the depression. Most of the supporting evidence for the serotonin hypothesis after the 1980s has been just exactly this. From the patients' response to the SSRIs, the inference is drawn that the cause of the disorder is a lack of serotonin. Drugs are used to probe and understand mental disorders yet this method functions entirely within the realm of symptomology. Nature refuses to reveal her true causes from the mere control of symptoms.

Depression is a complex mental disorder. Whether it is a disease with an organic origin is another matter. None the less, the current focus on neurochemical abnormality has produced a "depression puzzle", in which the pieces simply do not add up. First, reserpine, an antipsychotic, produces depressive symptoms by depleting the brain of complex amines. ${ }^{\text {ii }}$ This should cause depression in all patients if the serotonin hypothesis were true, but it does not. Less than $20 \%$ of patients will become depressed. Second, Max Lurie and Harry Salzer used the antidepressant drug, isoniazid, in the 1950s with two out of three patients responding, but isoniazid has no action on the serotonin system (Healy, ${ }^{8} \mathrm{p}$ 52). So, the same kind of evidence (drug action) that is used in support of the serotonin hypothesis also counts against it. Third, there has been a gradual increase in depression around the world, culminating in what has been called the "era of depression" in the 1990s. ${ }^{14}$ If, however, the serotonin hypothesis is true, this must be because there is a corresponding gradual increase in defective serotonergic systems around the world. There is no evidence for this implausible idea. Finally, twice as many women as men are likely to become depressed, which must mean that women are born with a less effective serotonergic system. Again there is no evidence for this either.

Suppose that we dispose altogether of the serotonin hypothesis as an attempt to understand the aetiology of depression. What counts most in medicine are statistical correlations establishing varying degrees of reliability, and according to the advocates of SSRIs, their reliability (effectiveness and safety) is clearly established. The plain and simple fact of the matter (so it is said) is that millions of patients have been relieved of their debilitating depression,

ii This is described by Flores in the article in the Textbook of Psychopharmacology. ${ }^{12}$ This widely used classic of psychopharmacology provides the standard evidence in favour of the serotonin hypothesis but fails to discuss any evidence against the theory. This problem is repeated in Nemeroff's paper in Scientific American. ${ }^{13}$ some of them in dramatic and unmistakable ways. How could this possibly be explained if the SSRIs are not effective treatments?

The clinical trials that form the basis of Food and Drug Administration (FDA) approval of SSRIs demonstrate repeatedly that these drugs show a clinically negligible advantage over inert placebo (sugar pills) in the treatment of depression. Here we must keep in mind that the data from clinical trials rank at the top of the hierarchy of evidence in the world of psychopharmacology. FDA approval, however, only requires that the drugs are better than nothing. According to the best data available, there is a less than $10 \%$ difference in the effect of FDA approved antidepressants versus placebo. ${ }^{15}{ }^{16}$ In some studies, placebo control groups duplicated $80 \%$ of the response to medication. ${ }^{17-19}$ The studies that provide the desired results, embarrassingly minimal as they are, reach publication and appear in the databases of the pharmaceutical companies and the FDA. What the general public barely sees are many of the failures of clinical trials around the world and the clinical trials that are prematurely terminated due to adverse side effects. These failed studies never see the light of day because the pharmaceutical companies that fund the studies own the data that is produced from the contract research organisations and site management organisations. The control over the data also enables the companies to provide the spin on the data that favours their drugs. ${ }^{2021}$

\section{MARKETING DEPRESSION}

No one knows exactly how SSRIs work, if indeed they really do work at all. One plausible explanation is that they mask symptoms of depression in moderate cases that resolve themselves spontaneously. It is also well known that the more a drug is hyped in the mainstream media as a "miracle drug", the greater is the likelihood of a strong placebo effect. What is, however, fundamentally problematic from an ethical point of view is the over inflation of SSRI effectiveness and safety, questionable marketing strategies, and the megadose prescriptions that can alter brain chemistry and behaviour for the worse.

Pharmaceutical companies in their direct to consumer marketing continue to promote SSRIs in television advertisements with the catchy suggestion: "While the cause of depression is not known, you might be suffering from a chemical imbalance. Ask your physician about [SSRI trade name]". Website advertisements for certain SSRIs claim their non-habit-forming drugs "correct the chemical imbalance believed to cause the disorder" and include diagrams of how this "science" works. In this manner, the companies "grow the market" by increasing consumer awareness of depression and target larger populations for their drugs. Direct to consumer advertising increases the request rates of the drugs and brand choices as well the likelihood that these drugs will be prescribed by physicians and psychiatrists. ${ }^{\text {iii }}$

The idea of selling us depression, whether we are truly ill or not, has become an immensely lucrative strategy for selling SSRIs, a large part of which succeeds on the basis of the idea of chemical imbalance. The range of prescriptions for SSRIs has included severe, chronic depression (completely nonfunctional human beings); moderate cases of depression (precipitated by stress, loss of loved ones, rape, divorce, professional failure), and the completely ludicrous (the angst ridden, ill adjusted child, personality sculpting, and psychotherapeutic fashion). The marketing strategy plays on the public's desire for a quick fix for all the vicissitudes of life and the power of the suggestion contained in the easy to

\footnotetext{
iii Direct to consumer advertising of pharmaceuticals is prohibited in every country except the United States and New Zealand. ${ }^{22}$
} 
understand model of chemical imbalance. This phenomenon has been dubbed the "medicalisation of society" - a phrase coined to describe the belief that every problem requires medical treatment, which is particularly relevant in the case of antidepressants. A report by the UK House of Commons health committee attributes this to the activities of the pharmaceutical industry. ${ }^{23}$ However, the strategy also works so well because of the public's ignorance of, and trust in, the institution of science-there will always be those who know these marvellous things beyond the reach of ordinary people and they offer these amazing solutions to problems that just yesterday we did not understand. SSRIs have been abused as lifestyle drugs or performance enhancement drugs in the manner of LSD, Viagra, or anabolic steroids. The pharmaceutical companies have benefited from this trend to the tune of ten billion dollars per year from sales of all SSRIs. The problem begins here. The industry is marketing the condition and then the lifelong commitment to their products. ${ }^{24} 25$ Although patients might gain a short term solution from SSRI prescriptions, the long term harm is only just starting to come into focus for both individuals and the institution of medicine.

Marketing departments employ a strategy they call "evergreening" by beginning with one indication of a use for an SSRI and then moving on to explore other "green" pastures for potential markets. In order to convince people something is wrong with them that requires SSRI therapy, the marketing departments hire public relations firms to raise awareness of a newly approved indication, sometimes using celebrity spokespersons to pitch the idea. SSRIs were first marketed for depression, then for panic disorder, obsessive compulsive disorder, post traumatic stress disorder, seasonal affective disorder, generalised anxiety disorder, and social anxiety disorder. Other potential indications in the marketing strategy that show up in clinical trials include premature ejaculation and paedophilia (since we know SSRIs cause sexual dysfunction), premenstrual syndrome, writer's block, obesity, alcoholism, cocaine addiction, compulsive shopping, and smoking cessation.

Healy explains how the so called "depression epidemic" developed from psychiatric concerns over unrecognised and untreated depression in the 1960s and 1970s. National depression campaigns were mounted in the United States and the United Kingdom. These involved alerting physicians and third party payers in health care to the huge economic burdens of untreated depression and educational campaigns to shame physicians for failing to detect and treat depression (Healy, ${ }^{8}$ p 43). The infusion of industry money into psychiatry means influence on the very definitions of psychological disorder that determine how a patient will be diagnosed and treated. ${ }^{\text {iv }}$ In this manner, depression is understood to be a physiological disease that is treated by drugs like SSRIs and thereby gains the imprimatur of organisations like the American Psychiatric Association.

Pharmaceutical companies effectively control many professional conferences and medical journal publications, employ psychiatrists as "key opinion leaders" and pay them handsomely to sign on to publications ghost written by their

iv The psychological disorder "social phobia" was replaced by the marketable "social anxiety disorder", which falls within the generic category of "depressive illness" now treatable with SSRIs. Since simple cases of shyness are on a continuum with social phobia, SSRIs have been prescribed for the former without any real assessment of the risks or the legitimacy of the very idea of such nosology. SmithKline Beecham's business plan ${ }^{26}$ is a rare glimpse of how sales reps are encouraged to prepare themselves "to take full advantage of the opportunity Social Anxiety Disorder provides to differentiate Paxil, grow our market share and achieve our super bonus goal of passing Zoloft and attaining \$1.5 billion in sales. Let's get psyched!" own staff or medical communication agencies employed by the company. The practice of for profit, industry sponsored ghost writing has become a major concern since scientific journals are meant to be neutral arbiters of merit via the critical peer review process. ${ }^{27}{ }^{28}$ Marketing interests have, however, tainted some of the most distinguished journals in medicine, especially psychiatry. The marketing of depression has spread to the very highest levels now that the distinction between promotional materials and scientific objectivity has been blurred. Academics who are expected to be the legitimate authors of journal articles turn out to be little more than ornaments to a business rushing to gain blockbuster status for its drugs or instruments used in the competition between the various companies to dominate the market share. ${ }^{29 \mathrm{v}}$

Is life really so much more stressful today than it was 20 or 30 years ago or has the marketing strategy of the pharmaceutical companies succeeded in convincing us that we are depressed and cannot cope without their drugs? Approximately 50 to 100 people per million were thought to be depressed before the creation of antidepressants; today our best estimates put the figure at 100,000 to 200,000 people per million (Healy, ${ }^{8}$ p 20). A third possibility is that all these depressed people were previously walking the streets undiagnosed. If this was the idea of well intentioned psychiatrists forty years ago, it has been exploited with maximum financial results by pharmaceutical marketing departments.

\section{HIDDEN DANGERS}

Within the controlled environment of clinical trials it is possible to limit variables to determine the efficacy of the study drug versus placebo and identify the likely cause of adverse reactions. With regard to the latter, this typically comes down to two possibilities: the underlying disorder or the study drug. Despite many cases in which the investigator identifies the study drug as the definite or probable cause of the adverse reaction, the pharmaceutical companies consistently blame the underlying disorder rather than the treatment. In the parlance of the industry, this is known as "defending the molecule". The more serious adverse reactions that show up in clinical trials and spontaneous reports include: akathisia; aggression; self mutilation; emotional blunting; worsening depression; withdrawal symptoms, and suicidality. The latter two were a major concern with the introduction of the SSRIs and have been the focus of considerable debate in the medical literature.

Given that the serotonin hypothesis of depression emerged partly from an examination of serotonin levels in suicide victims, there has been a theoretical resistance from the start to the very idea that SSRIs could be responsible for some cases of suicide. While it is clear that depressed patients are at a higher risk of suicide, what is particularly problematic for the claim that any suicidal thoughts or attempts while on an SSRI are always caused by the underlying disorder is the lack of any suicidal history in many of these patients. Moreover, some patients on SSRIs for indications other than depression or in healthy volunteer studies become suicidal. Numerous cases of this sort caused alarm among researchers in the early 1990s. ${ }^{32}{ }^{33}$ A common side effect of SSRIs is akathisia-a drug induced condition of extreme restlessness, insomnia, and agitation that is accompanied by compulsions to commit violence to oneself or to others. ${ }^{34-36}$ Many patients will say that they "feel like a video on fast forward" or that they "just want to jump out of their skin" and see suicide as the only relief. The most disturbing cases on record concern functional

${ }^{\vee}$ See my case study in the Hastings Center Report for direct evidence of ghost writing ${ }^{30}$ and the discussion of this in a speech by Paul Flynn MP. ${ }^{31}$ 
individuals with moderate depression caused by some change of life who are prescribed an SSRI, become extremely agitated and restless, and then commit suicide within a matter of days or weeks - this being completely out of character with anything in their past. Patients of this sort are more than likely to be seen by primary care physicians who have not been trained to recognise the problem of akathisia. Their doctors will typically misdiagnose the symptoms as worsening depression and the suicides as a result of the underlying disorder-consistently with the approach of the marketing departments of the pharmaceutical companies.

The FDA and the drug companies have constantly argued that no causal relationship has been established between suicide and SSRIs despite the existence of many adverse drug experience reports. There are, however, indications that the sheer volume of these reports together with the ones from clinical trials are starting to command attention in psychiatry and general practice. Studies have been done by pharmaceutical companies that provide evidence for the causal relationship-namely, the method of determining causality: challenge, dechallenge, rechallenge. In this process a patient is given a drug and experiences a side effect (challenge), then the drug is discontinued and the side effect disappears (dechallenge), and finally the drug is reintroduced and the same side effect appears again (rechallenge). Suicidality is regularly coded as caused by the study drug by the investigators and the sponsor. What is even more revealing about the extent to which the pharmaceutical companies are willing to press the point is that discussions about side effects of drugs take on the character of something approaching a rigorous Humean scepticism with regard to the very meaning of the term "cause", but when the issue is efficacy the term suddenly has a perfectly clear meaning. SSRIs, we are told, do cause relief of depression. The serious side effects, such as suicidality, are merely unproved "associations".

In regulatory actions that were long overdue, the FDA issued a pair of warnings for SSRIs, both of which concern suicidality. On 22 March 2004, the FDA required antidepressant manufacturers to include in their label a warning statement that recommends close observation of adult and paediatric patients treated with these agents for worsening depression or the emergence of suicidality, "especially at the beginning of therapy or when the dose either increases or decreases". Then on 15 October 2004, the FDA, faced with public pressure from a recent action by UK regulators, followed up with the strongest warning possible-the "black box" warning-which describes the increased risk of suicidality in children and adolescents on SSRIs. ${ }^{38} 39$

Determining causality in SSRI/suicide cases is enormously complex. According to some studies we must distinguish between SSRI induced suicidality in children or adolescents, and adults: the former indicates a risk of suicide probably increased under SSRI therapy whereas the latter shows no increased risk. ${ }^{40}$ The main evidence focuses attention on (1) the data comparing SSRI and tricyclics, which shows that users of SSRIs are not at any more risk of suicidality than those on tricyclics, ${ }^{41}$ and (2) the failure of the SSRI/suicide cases to reach a statistical significance compared to placebo/ suicide cases. ${ }^{42}{ }^{43} 44$ According to other studies the data from adult studies shows a twofold increase in the risk of fatal and non-fatal suicidal attempts in users of SSRIs compared to users of placebo, and this has been exactly what the data has shown since the introduction of the SSRIs. ${ }^{45}$ Aursnes et al argue that Cipriani et al failed to convey the unanimous conclusion in the reviewed studies of an increased risk of suicidal attempts in adult patients on SSRIs. ${ }^{46}$

Many patients on SSRIs describe their experience as a "chemical prison". Once started on a regime, the attempt to reduce the dosage or discontinue the drug without experiencing severe adverse events can be very difficult. These include jolting electric zaps (paraesthesia); confusion; headaches; vomiting; dizziness; nausea; worsening depression; insomnia; irritability; emotional lability, including suicidality, and agitation that, when severe, can resemble a manic episode. A small percentage of patients claim they literally cannot get off the drugs even if they try and taper off the dosage. Pharmaceutical companies have vigorously maintained that SSRIs are not addictive and that what is believed to be withdrawal symptoms is really evidence that the drug is working. Since the adverse events that result from cessation of drug therapy are often confused with the reemergence of the depressive illness, physicians typically advise their patients to continue their regime or increase the dosage. The most compelling evidence against the drugs, however, comes in the form of withdrawal symptoms in neonatals whose mothers were on SSRIs during pregnancy. In such cases, it is not possible to blame the adverse events on re-emergence of depression. ${ }^{47-49}$

The problem of withdrawal emerged first with paroxetine because of the great volume of reports on the adverse event reporting system. Paroxetine has a relatively short half life (21-24 hours) and shorter washout period compared to fluoxetine (4 to 16 days), so the withdrawal symptoms tend to be more severe upon abrupt discontinuation. In a feat of semantic opportunism, the maker of fluoxetine, Eli Lilly, launched a public relations campaign to replace "withdrawal symptoms" with "discontinuation symptoms". The alleged difference is that the latter does not imply addiction as with the case of alcohol or barbiturates. Over time, however, it has become more and more difficult to maintain this position despite the enormous amount of money that funded conferences and medical journal supplements on the topic. ${ }^{\mathrm{vi}}$

The crux of the matter concerns the very meaning of "addiction". Psychiatrists who framed the definition in the third and fourth editions of The Diagnostic and Statistical Manual of Mental Disorders (DSM III and IV) had in mind diagnostic criteria identifying substance dependencenamely, maladaptive behaviour, euphoria, or compulsive drug seeking..$^{50}$ The classic cases of iatrogenic dependence in which the chemical system of the brain attempts to regain equilibrium no longer counts as addiction. This allowed the manufacturer of paroxetine, SmithKline Beecham (now GlaxoSmithKline), to claim in the patient's leaflet and in advertising that paroxetine is not addictive or habit forming. However, to patients suffering from withdrawal symptoms after discontinuing the drug, their physical dependence accorded with the common dictionary meaning of "addiction". In the Oxford English Dictionary, for example, "addiction" is defined as "the condition of taking drugs excessively and being unable to cease doing so without adverse effects". ${ }^{51}$ In this latter sense, one can become "hooked" on SSRIs without exhibiting drug seeking behaviour or becoming completely non-functional.

For those who have followed the rise and fall of drugs in the marketplace, the SSRIs merely repeat a familiar pattern. The drug companies and regulators had claimed that benzodiazepines were not addictive for well over a decade, but eventually it was admitted that tranquilisers such as diazepam (Valium) were indeed addictive. ${ }^{16}$ Glenmullen describes a "10-20-30" year pattern typical of side effects of popular psychiatric drugs-ten years for side effects to be identified, twenty years for enough data to accumulate to

vi A whole issue of The Journal of Clinical Psychiatry in 1997 was devoted to Antidepressant Discontinuation Syndrome. These papers were presented by opinion leaders at the closed symposium "SSRI Discontinuation Events" held 17 December 1996, in Phoenix, Arizona, sponsored by Eli Lilly. 
make the problem undeniable, and then thirty years for bureaucracies of regulatory agencies to make changes. ${ }^{52}$ Of course, it still remains to be seen whether the SSRIs will follow this pattern to the same conclusion.

\section{CONCLUSION}

It is often claimed that corporations that are profit driven could not be expected to behave in any other manner than they do. The nature of business demands maximisation of the market share and shareholder value. Pharmaceutical companies, however, present themselves as responsible producers of healthcare products. The very nature of the product involves trust in the science that produced it and an ethical commitment to the wellbeing of the patients who are their consumers. Despite appearances, nothing of this sort is true in the pharmaceutical industry.

As we have seen above, the serotonin hypothesis sold to consumers of pharmaceuticals is flawed. Making questionable claims for the efficacy and safety of SSRIs involves the pharmaceutical companies in further deception. Expanding the market for these drugs by creating dubious disease categories and then luring vulnerable individuals into SSRI therapy by direct to consumer advertising would represent, if perpetrated by a doctor, an abuse of the trust implicit in the relationship between patient and doctor.

I do not argue that SSRIs should be withdrawn from the market thus depriving clinicians and patients of this therapeutic option. Rather I argue that full disclosure of the data for efficacy and safety is a basic moral obligation of the pharmaceutical industry. Until such data is available to the public, prescribing clinicians and patients are relying on drug promotion rather than rigorous science. When Kant discusses the motivation of acting from duty as opposed to the motivation of self interest, he mentions the case of the merchant who keeps a fixed price for everyone so that a child who buys from him pays the same price as everyone else. ${ }^{53}$ The only actions that have moral worth are those done from the motive of duty alone. And similarly, only when the pharmaceutical companies act from the motive of duty in fully disclosing all information they possess about the risks and benefits of their drugs do their actions have any moral worth.

The SSRI marketing story provides a lens through which we can view a much larger problem. The integrity of medicine is endangered by an industry that profits from illness and distorts the process of scientific inquiry by marketing strategy, public relations campaigns, and the sheer power of buying influence in high places. The House of Commons health committee in the UK has made the point: "It is not in the long term interest of industry for prescribers and the public to lose faith in it. We need an industry which is led by the values of scientists not those of its marketing force" (House of Commons health committee, ${ }^{23}$ p 6). Medicine desperately needs to win back the territory lost to business. If and when it does, it is not likely to be a result of industry and government regulators facing up to the problems, but rather a matter of the sheer weight of legal actions filed by victims and public outcry about the moral concerns of the sort raised in this paper.

\section{DISCLOSURE}

Since 2003, the author has been a research consultant with the Baum-Hedlund Law Firm, Los Angeles, California.

\section{ACKNOWLEDGEMENT}

I wish to thank Skip Murgatroyd, David Healy, Ariel Eytan, Carl Elliott, Rebecca Whisnant, and Ann Lloyd for various forms of input to this paper.

\section{REFERENCES}

1 Healy D. The antidepressant era. Cambridge: Harvard University Press, 1997:155-69.

2 Healy D. The psychopharmacologists [vols 1 and 3]. London: Altman, 2000.

3 Ashcroft GW, Sharman DF. 5-Hydroxyindoles in human cerebrospinal fluids. Nature 1960;186:1050-1.

4 Ashcroft GW, Crawford TBB, Stanton JB, et al. 5-Hydroxyindole compounds in the cerebrospinal fluid of patients with psychiatric or neurological diseases. Lancet 1966;2:1049-52.

5 Ashcroft GW, Eccleston D, Murry LG, et al. Modified amine hypothesis for the aetiology of affective illness. Lancet 1972;2:573-7.

6 Åsberg M, Eriksson B, Mårtensson B, et al. Therapeutic effects of serotonin uptake inhibitors in depression. J Clin Psychiatry 1986;47(suppl 4):23-35S

7 Kramer PD. Listening to prozac. New York: Penguin Books, 1993, especially ch 3.

8 Healy D. Let them eat Prozac: the unhealthy relationship between the pharmaceutical industry and depression. Toronto: James Lorimer, 2003

9 Ashcroft G. The receptor enters psychiatry. In: Healy D, eds. The psychopharmacologists [vol 3]. London: Arnold, 2000:194.

10 Healy D. The structure of psychopharmacological revolutions. Psychiatr Dev 1987; 4:349-76

11 Antonuccio DO, Burns DD, Danton WG. Antidepressants: a triumph of marketing over science? Prevention \& Treatment. www.journals.apa.org/ prevention/volume5/pre0050025c.htm (accessed 19 Jun 2004).

12 Flores BH, Musselman DL, DeBattista C, et al. Biology of mood disorders. In: Schatzberg AF, Nemeroff CB, eds. Textbook of psychopharmacology [3rd] ed]. Washington DC: American Psychiatric Publishing, 2004:718.

13 Nemeroff CB. The neurobiology of depression. Scientific American 1998;278:2-9

14 Healy D. Psychopharmacology and the government of the self. www.pharmapolitics.com (accessed 4 May 2004).

15 Smith DC. Antidepressant efficacy. Ethical Hum Sci Serv 2000;2/3:215-16.

16 Medawar C. The antidepressant web: marketing depression and making medicines work. Int J Risk Safety Med 1997; 10:86-91

17 Kirsch I, Moore TJ, Scoboria A, et al. The emperor's new drugs: an analysis of antidepressant medication data submitted to the US Food and Drug Administration. Prevention and Treatment. www.journals.apa.org/ prevention/volume5, pre0050023a.html (accessed 14 May 2004).

18 Carroll BJ. Sertraline and the Cheshire cat in geriatric depression. Am J Psychiatry 2004;161:759.

19 Kirsch I, Moncrieff J. Efficacy of antidepressants in adults. BMJ 2005;331:155-7.

20 Bodenheimer T. Uneasy alliance: clinical investigators and the pharmaceutical industry. N Engl J Med 2000;342:1539-44 at 1541.

21 Whittington CJ, Kendall T, Fonagy $P$, et al. Selective serotonin reuptake inhibitors in childhood depression: systematic review of published versus unpublished data. Lancet 2004;363:1341-5.

22 Angell M. The truth about the drug companies: how they deceive us and what to do about it. New York: Random House, 2004:125.

23 House of Commons Health Committee. The influence of the pharmaceutical industry vol 1. London: The Stationery Office, 2005:100.

24 Wolfe SM. Profitably inventing new diseases. Health Letter 2003;19:2-3.

25 Moynihan R, Cassels A. Selling sickness: how the world's biggest pharmaceutical companies are turning us all into patients. New York: Nation, 2005.

26 SmithKlineBeecham's business plan guide December 1 1997-May 31, 1998, http://abcnews.go.com/Health/story?id = 31 1956\&page-1 (accessed 12 Sept 2005).

27 Davidoff F, DeAngelis CD, Drazen JM, et al. Sponsorship, authorship, and accountability. N Engl J Med 2001;345:825-7

28 Flanagin A, Carey LA, Fontanarosa PB, et al. Honorary authors and ghost authors in peer reviewed medical journals. JAMA 1998;280:222-4.

29 Healy D, Cattell D. Interface between authorship, industry and science in the domain of therapeutics. Br J Psychiatry 2003;183:22-7.

30 McHenry L. On the origin of great ideas: science in the age of big pharma. Hastings Cent Rep 2005;35:17-19.

31 Flynn P. House of Commons official report: col 1038. www.parliament. the-stationery-office.co.uk/pa/cm200506/cmhansrd/cm051208/debtext/ 51208-18.htm (accessed 16 Feb 2006) (Hansard).

32 Teicher MH, Glod C, Cole JO. Suicidal preoccupation during fluoxetine treatment. Am J Psychiatry 1990;147:1380-1.

33 Masand P, Gupata S, Dewan M. Suicidal ideation related to fluoxetine treatment. N Engl J Med 1991;324:420.

34 LaPorta L. Sertraline-induced akathisia. J Clin Psychopharmacology 1993;13:219-20.

35 Healy D, Langmack C, Savage M. Suicide in the course of treatment of depression. J Clin Psychopharmacology 1999;13:94-9.

36 Breggin PR. Toxic psychiatry: why therapy, empathy and love must replace the drugs, electroshock, and biochemical theories of the "new psychiatry". New York: St Martin's Press, 1991:167.

37 Maris RRM. Suicide and neuropsychiatric adverse effects of SSRI medications: methodological issues. http://www.oism.info/en/therapy/theory/ suicide_and_neruopsychiatric_adverse_effects_of_ssri.htm (accessed 16 Feb 2006).

38 www.fda.gov/bbs/topics/news/2004/NEW01124.html laccessed 13 May 2005)

39 www.fda.gov/cder/drug/antidepressants/AntidepressantPHA.htm (accessed 13 May 2005).

40 Cipriani A, Barbui C, Geddes JR. Suicide, depression, and antidepressants. BMJ 2005;330:373-4. 
41 Martinez C, Riebrock S, Wise L, et al. Antidepressant treatment and the risk of fatal and non-fatal self harm in first episode depression: nested case control study. BMJ 2005;330:389-93.

42 Kahn A, Warner HA, Brown WA. Symptom reduction and suicide risk in patients treated with placebo in antidepressant clinical trials. Arch Gen Psychiatry 2000;57:311-17.

43 Khan A, Khan S, Kolts R, et al. Suicide rates in clinical trials of SSRIs, other antidepressants, and placebo: an analysis of FDA reports. Am J Psychiatry 2003; 160:790-2

44 Gunnell D, Saperia J, Ashby D. Selective serotonin reuptake inhibitors (SSRIs) and suicide in adults: meta-analysis of drug company data from placebo controlled, randomised controlled trials submitted to the MHRA's safety review. BMJ 2005;330:385-8.

45 Fergusson D, Doucette S, Glass KC, et al. Association between suicide attempts and selective serotonin reuptake inhibitors: systematic review of randomised controlled trials. BMJ 2005;330:396-9.

46 Aursnes I, Tvete IF, Gaasemyr J, et al. Suicide attempts in clinical trials with paroxetine randomised against placebo. BMC Medicine 2005;3:14
47 Nordeng $\mathbf{H}$, Lindemann $\mathrm{R}$, Perminov KV et al. Neonatal withdrawal syndrome after in utero exposure to selective serotonin reuptake inhibitors. Acta Paediatr $2001 ; 90: 288-91$

48 Sanz EJ, De-las-Cuevas C, Kiuru A, et al. Selective serotonin reuptake inhibitors in pregnant women and neonatal withdrawal syndrome: a database analysis. Lancet 2005;365:482-7.

49 Medawar C, Hardon A. Medicines out of control? Antidepressants and the conspiracy of goodwill. Amsterdam: Aksant Academic Press, 2004:84.

50 American Psychiatric Association. Diagnostic and statistical manual of mental disorders [4th ed]. Washington, DC: APA, 2000:192-9.

51 Sykes JB. The concise Oxford dictionary of current English. Oxford: Clarendon Press, 1984:11.

52 Glenmullen J. The antidepressant solution: a step by step guide to safely overcoming antidepressant withdrawal, dependence and "addiction". New York: The Free Press, 2005:190-1.

53 Kant I. The fundamental principles of the metaphysic of morals [trans Abbott TK]. London: Longmans, Green and Co, 1946:15. 